\title{
Analysis of the Level of Emotional Intelligence among Executives in Small and Medium Sized Enterprises
}

\author{
Susan Tee Suan Chin, R.N. Anantharaman and David Yoon Kin Tong \\ Multimedia University, Malacca, Malaysia
}

\begin{abstract}
The purpose of this research is to study the level of emotional intelligence among executives in small and medium sized enterprises particularly from the manufacturing sector. SMEs have problems in attracting and retaining their employees. For the purpose of the study, the GENOS Emotional Intelligence questionnaire developed by Palmer and Stough (2001) has been used. A total of 96 employees from different manufacturing sectors took part in the survey. It was found that emotional intelligence did not have a significant relationship with organizational citizenship behaviour. Results from the study show that employees in the SMEs do experience some kind of experiences that affect their working attitudes. The initial study provides many insights especially to the areas where respondents show a low level of emotional intelligence. The low level of emotional intelligence is related to the nature of work involved especially when it involves a high level of stress.
\end{abstract}

Keywords: small and medium sized enterprises, emotional intelligence, organizational citizenship behaviour

\section{Introduction}

The importance and contributions of small and medium sized enterprises (SMEs) or organizations to the country cannot be dismissed. SMEs represent a large percentage of establishments in Malaysia [SMIDEC 2009]. $99.2 \%$ of established organizations are from SMEs, while the remainder belongs to the larger organizations. SMEs contribute $32 \%$ to Gross Domestic Product (GDP) and they employ $56.4 \%$ of the total workforce of the country. SMEs represent an important backbone to the Malaysian economy especially on the unemployment issue [Che Rose, Kumar, and Lim, 2006]. Many studies have showed that only $10 \%$ of the SMEs survived beyond the 10 years mark [CCM 2002].

The services and manufacturing sector are expected to take in substantial amounts of people by the year 2010 [JobStreet 2009]. The manufacturing sector will remain as the vital engine to spur growth for the Malaysian economy, and SMEs are a major contributor to it. However, the challenges that SMEs face are focused towards the people. They have problems in attracting and retaining talented employees. They need to enhance the competencies and the innovativeness of the workforce so that they will be able to compete in the global market. However, this problem is not prevalent in Japan where the

Copyright (C) 2011 Susan Tee Suan Chin, R.N. Anantharaman and David Yoon Kin Tong. This is an open access article distributed under the Creative Commons Attribution License unported 3.0, which permits unrestricted use, distribution, and reproduction in any medium, provided that original work is properly cited. Contact author: Susan Tee Suan Chin E-mail: tschin@mmu.edu.my 
concept of "lifetime employment" is deeply rooted [DeloitteKassimChan 2009].

However, Cooper [1998] has showed that emotions when properly managed, drives trust, loyalty and commitment among the employees. Through this, there would be productivity gains, high level of innovations coupled with organisational accomplishments. Hence, the objectives of this research are:

1) To examine the relationship between emotional intelligence and organisational citizenship behaviour together with their dimensions.

2) To explore the relationship between the demographic variables and emotional intelligence in particular, age, length of employment and department.

By definition, SMEs in Malaysia would fall into the categories of those organizations having less than 150 employees. Abdul Hamid, Baharun and Hashim [2008] state that the most common problems faced by SMEs include recruiting and selecting good and dedicated employee. These account for $49.5 \%$ and $36.9 \%$ respectively.

Based on Cooper's [1998] findings on "managed emotions", human resources problems faced by SMEs can be resolved if there were some training programmes conducted for the employees. However, more importantly, there is a need to know the level of emotional intelligence that exists among executives in the SMEs as well as their relationship towards the expected behaviours.

\section{Emotional Intelligence and Employee Engagement}

Mayer and Salovey [1997] have defined emotional intelligence as "the ability to perceive emotions, to access and generate emotions so as to assist thought, to understand emotions and emotional knowledge and to effectively regulate emotions so as to promote emotional and intellectual growth. When applied to the workplace, Emotional Intelligence involves the capacity to effectively perceive, express, understand and manage emotions in a professional and effective manner at work [Palmer and Stough 2001]. According to the Genos EI developed by Palmer and Stough [2001] (previously named as Swinburne University Emotional Intelligence Unit), there are five key emotional competencies which are applicable to the workplace situation; these are Emotional Recognition and Expression, Understanding Others Emotions, Emotions Direct Cognition, Emotional Management and Emotional Control.

\section{Emotional Intelligence and Organisational Citizenship Behaviour}

Based on Watson Wyatt Malaysia [2009], employee engagement is important as part of the employee retention programme. Engaged employees will be better performers and will contribute positively to the company's financial performance. In this respect, employee engagement can be related to contextual performance. Results have showed that there is a strong link between employee engagement and rate of productivity [The Star 2009b]. Employee engagement can be related to organizational citizenship behaviour. Organisational citizenship behaviour includes all the extrarole, discretionary behaviour that helps other members in the organisation to perform their jobs. According to Podsakoff et al [1990], organizational citizenship behaviour has five elements that measures conscientiousness, sportsmanship, civic virtue, courtesy and altruism.

According to Abraham [2000], emotional intelligence enhances the altruistic behaviour of an individual. It enables employees to comprehend their fellow colleagues and to respond better than those with lower level of emotional intelligence. This is due to their ability to shift from negative moods to positive moods. Altruism refers to the act of helping others who have been absent or are 
behind in their work. It is sometimes called the wilful sacrifice of one's own interest or well-being for the sake of something that is non-self. Douglas, Frink and Ferris [2004] note that highly conscientious people with higher level of emotional intelligence performed better than those with a lower level of emotional intelligence. Deshpande and Joseph's [2005] study found that employees with a high level of emotional intelligence are able to counter negative behaviours. However, a study conducted by Sitter [30] disagrees with the results. Based on the research, the level of emotional intelligence has a positive but does not have a much significant factor to organizational citizenship behaviour. In a study conducted by Pasanen [2000], emotional intelligence was not found not to be a predictor of organizational citizenship behaviour. The differing results could be due to the nature and size of the sample. Hence, in this research, one of the objectives is to ascertain the relationship between emotional intelligence and organizational citizenship behaviour.

\section{Emotional Intelligence and Demographic Variables}

According to a study made by Boncher [2003], gender reveals a statistically significant interactional effect for Understanding Emotions. Based on Brooks [2002], management tenure does not have a significant impact of the level of emotional intelligence. Langhorn [2004] finds that experienced managers had a lower level of emotional intelligence than lesser experienced managers. Based on a research by Dolcos [2008], older people tend to be better at regulating and controlling their emotions than those who are younger. In terms of age and level of emotional intelligence, there seems to be some disagreement between the findings of Chipain [2003] and Langhorn in 2004. In Chipain's [2003] study, it is found that there is a positive and a significant correlation with the level of emotional intelligence and age. In Langhorn's [2004] study, age does not demonstrate any significance.

Similar findings were found by Lim [2004] based on his studies of 218 employees, age has no effect on the level of emotional intelligence. A study by Scott [2004] gives another insight: the level of emotional intelligence is said to have rose only after 40 years of age. Alloway [2004] finds that there are significant differences in the level of emotional intelligence among managers. Senior level managers scored a higher level of emotional intelligence in comparison with middle level managers. This gives an indication that the more experienced the employee, the higher would be his or her level of emotional intelligence. The differences in the results give ground for further research.

The manufacturing sector is famous for the "job-hopping illness" and this could be detrimental to the industry if it is not arrested [Mustapha and Abdullah 2005]. Jobhopping could be related to the type of occupation that the employee is involved with. If they typically deal with complaints lodged by customers, they would feel highly stressful [JobStreet 2009]. These occupations include: information technology, engineering, sales and marketing, finance and human resources, operations, production and clerical. If their stress levels are affected, then their level of emotional intelligence will be affected as well. Traumatic and significant events will have impacts on the behaviours of the employees [Mignonac and Herrbach 2004; Weiss and Cropanzano 1996]. Their attitudes would affect their performance at work. Based on a study by Rozell et. al. [2001], students majoring in accounting have a lower level of emotional intelligence in comparison with students majoring in management and finance. The second research objective is to examine the level of emotional intelligence among executives in small and medium sized industries. 


\section{Research Design}

\section{Sample Selection and Population}

Malaysian manufacturing industry has been chosen for the study because it represents one of the important driving forces and contributes to a sizeable portion to the Gross Domestic Product of Malaysian economy. In terms of the manufacturing sector, there has been a rise in job-hopping among employees [Mustapha and Abdullah 2005]. Melaka is one of four states in Malaysia which has attracted a considerable number of foreign investors.

There are about 469 manufacturing organisations in Melaka [MSDS 2007]. About 422 of them belong to small and medium sized organisations while the remaining have been categorised as large organisations. In this initial study, 8 companies have been randomly identified. A total of 96 executives from 8 different companies have taken part in the research study.

\section{GENOS EI Framework}

In terms of measuring the level of emotional intelligence, the GENOS Emotional Intelligence questionnaire developed by Palmer and Stough [1997] is used. The Genos EI model consists of five dimensions; recognising and expressing emotions, understanding emotions of others, making decisions, managing emotions and controlling emotions.

The Genos EI is reliable with $\alpha=0.88$ (Emotional Recognition and Expression : $\alpha=$ 0.73, Understanding of Emotions : $\alpha=0.83$, Emotions Direct Cognition : $\alpha=0.63$, Emotional Management : $\alpha=0.72$, Emotional Control : $\alpha=0.72$ ) It has been also shown to have good internal consistency and test retest reliability [Gardner and Stough 2002; Palmer 2003]. This test re-test reliability is an important aspect of the psychometric property of the emotional intelligence measurement. The test consists of 64 questions and takes about 12-15 minutes to complete. There are a balanced number of positively and negatively phrased items that will help to determine inconsistent patterns and also illogical responses by the respondents. There are 11 statements for Emotional Recognition and Expressions, 20 statements for Understanding Others Emotions, 12 statements for Emotions Direct Cognition, 12 statements for Emotional Management and 9 statements for Emotional Control.

According to the GENOS EI, there are five key emotional competencies which are applicable to the workplace situation:-

- Emotional Recognition and Expression refers to the ability to identify one's own feelings and emotional states and the ability to express those inner feelings to others.

- Understanding Others Emotions - refers to the ability to identify and understand the emotions of others and those that are manifest in response to workplace environments and staff meetings.

- Emotions Direct Cognition - refers to the extent to which emotions and emotional knowledge are incorporated in decisionmaking and \or problem solving situations.

- Emotional Management - refers to the ability to manage positive and negative emotions both within oneself and others

- Emotional Control - refers to the ability to effectively control strong emotional states experienced at work such as anger, stress, anxiety and frustration.

The questionnaire uses the five-point Likert scale $(1$ = strongly disagree, 2 = disagree, $3=$ neutral, 4 = agree, $5=$ strongly agree).

\section{Organisational Citizenship Behaviour Scale}

Organisational Citizenship Behaviour Scale developed by Podsakoff et al [1990] is used to measure contextual performance. The scale has five elements that measures 
conscientiousness, sportsmanship, civic virtue, courtesy and altruism.

- Conscientiousness - punctuality in attendance, use of work time and adherence to rules. It also refers to the trait of being painstaking and careful, or the quality of acting according to the dictates of one's conscience. It includes such elements as self-discipline, carefulness, thoroughness, organization, deliberation (the tendency to think carefully before acting) and need for achievement. It is an aspect of what was traditionally called character. Conscientiousness is related to emotional intelligence and impulse control.

- Altruism - helping others who have been absent or who have fallen behind in their work (any voluntary action that helps another person out at work) it is often referred to as the wilful sacrifice of one's own interests or well-being for the sake of something that is non-self. It is also often defined as being the selfless concern for the welfare of others.

- Sportsmanship - putting up with minor inconveniences, or not always finding fault with the organisation.
- Courtesy - consulting people who may be affected by a decision or at the very least informing other people in advance of such actions.

- Civic virtue - keeping up with developments happening in the organisation (being constructively involved in the political process of the organisation).

Like the GENOS EI, this questionnaire also uses the five-point Likert scale.

\section{Empirical Analysis}

\section{Respondents Analysis}

From Table 1, it can be noted that there are more males rather than females executives working the manufacturing industry. A majority of them are aged between 25 to 35 years of age, this accounted for $70.9 \%$. About fifty percent of them are working between 2 to 5 years. $10.4 \%$ of respondents have worked more than 10 years, this indicates that many of these employees are not willing to work longer in the SMEs. $39.6 \%$ of the respondents are working in Production indicating that there are few personnel working in the offices. 
Table 1: Demographic Analysis of Respondents

\begin{tabular}{|c|c|c|c|}
\hline Particulars & Items & Freq & $\%$ \\
\hline \multirow[t]{3}{*}{ Gender } & Male & 61 & 63.5 \\
\hline & Female & 35 & 36.5 \\
\hline & & 96 & \\
\hline \multirow[t]{6}{*}{ Age } & Less than 25 years old & 6 & 6.3 \\
\hline & More than 25 but less than 30 & 42 & 43.8 \\
\hline & More than 30 but less than 35 & 26 & 27.1 \\
\hline & More than 35 but less than 40 & 16 & 16.7 \\
\hline & More than 40 years old & 6 & 6.3 \\
\hline & & 96 & \\
\hline \multirow{5}{*}{$\begin{array}{l}\text { Employment } \\
\text { Length }\end{array}$} & Less than 2 years & 17 & 17.7 \\
\hline & More than 2 years but less than 5 years & 54 & 56.3 \\
\hline & More than 5 years but less than 10 years & 15 & 15.6 \\
\hline & More than 10 years & 10 & 10.4 \\
\hline & & 96 & \\
\hline \multirow[t]{8}{*}{ Department } & Administration & 15 & 15.6 \\
\hline & Finance and Accounting & 10 & 10.4 \\
\hline & Production & 38 & 39.6 \\
\hline & Sales and Marketing & 21 & 21.9 \\
\hline & Maintenance & 2 & 2.1 \\
\hline & Engineering & 5 & 5.2 \\
\hline & Others & 5 & 5.2 \\
\hline & & 96 & \\
\hline
\end{tabular}

\section{Emotional Intelligence and Organisational Citizenship Behaviour}

With reference to Table 2 , it is found that emotional intelligence has no significant relationship with organizational citizenship behaviour. The present study agrees with the findings of Sitter [2004] and Pasanen [2000] who found that emotional intelligence does not have a much significant factor with organizational citizenship behaviour. This is contrary to the belief that having a high level of emotional intelligence would automatically result in a high level of organizational citizenship behaviour.

Table 2: Relationship between the Level of Emotional Intelligence and Organizational Citizenship Behaviour

\begin{tabular}{|l|l|l|l|}
\hline & & $\begin{array}{l}\text { Level of } \\
\text { Emotional } \\
\text { Intelligence }\end{array}$ & $\begin{array}{l}\text { Level of } \\
\text { Organisational } \\
\text { Citizenship } \\
\text { Behaviour }\end{array}$ \\
\hline $\begin{array}{l}\text { Level of Emotional } \\
\text { Intelligence }\end{array}$ & $\begin{array}{l}\text { Pearson } \\
\text { Correlation }\end{array}$ & 1 & .114 \\
\hline & Sig. (1-tailed) &. & .135 \\
\hline & $\mathrm{N}$ & 96 & 96 \\
\hline
\end{tabular}


7 Journal of Human Resources Management Research

Table 3: Relationship between the Dimensions of Emotional Intelligence and the Dimensions of Organizational Citizenship Behaviour

\begin{tabular}{|l|l|l|l|l|l|}
\hline & Conscientiousness & Sports-manship & Civic Virtue & Courtesy & Altruism \\
\hline ERE & $\mathrm{r}=-0.168$ & $\mathrm{r}=0.009$ & $\mathrm{r}=0.071$ & $\mathrm{r}=0.250^{* *}$ & $\mathrm{r}=-0.223^{*}$ \\
& $\mathrm{p}=0.051$ & $\mathrm{p}=0.464$ & $\mathrm{p}=0.246$ & $\mathrm{p}=0.007$ & $\mathrm{p}=0.015$ \\
\hline UOE & $\mathrm{r}=0.275^{* *}$ & $\mathrm{r}=-0.182^{*}$ & $\mathrm{r}=0.369^{* *}$ & $\mathrm{r}=0.117$ & $\mathrm{r}=0.171^{*}$ \\
& $\mathrm{p}=0.003$ & $\mathrm{p}=0.038$ & $\mathrm{p}=0.000$ & $\mathrm{p}=0.128$ & $\mathrm{p}=0.048$ \\
\hline EDC & $\mathrm{r}=0.566^{* *}$ & $\mathrm{r}=-0.648^{* *}$ & $\mathrm{r}=0.517^{* *}$ & $\mathrm{r}=0.455^{* *}$ & $\mathrm{r}=0.450^{* *}$ \\
& $\mathrm{p}=0.000$ & $\mathrm{p}=0.000$ & $\mathrm{p}=0.000$ & $\mathrm{p}=0.000$ & $\mathrm{p}=0.000$ \\
\hline EM & $\mathrm{r}=0.150$ & $\mathrm{r}=-0.191^{*}$ & $\mathrm{r}=0.094$ & $\mathrm{r}=-0.028$ & $\mathrm{r}=0.202^{*}$ \\
& $\mathrm{p}=0.072$ & $\mathrm{p}=0.031$ & $\mathrm{p}=0.181$ & $\mathrm{p}=0.394$ & $\mathrm{p}=0.024$ \\
\hline EC & $\mathrm{r}=0.294^{* *}$ & $\mathrm{r}=-0.346^{* *}$ & $\mathrm{r}=0.097$ & $\mathrm{r}=0.313^{* *}$ & $\mathrm{r}=0.268^{* *}$ \\
& $\mathrm{p}=0.002$ & $\mathrm{p}=0.000$ & $\mathrm{p}=0.174$ & $\mathrm{p}=0.001$ & $\mathrm{p}=0.004$ \\
\hline
\end{tabular}

* Correlation significant at the 0.05 level ( 1 tailed)

** Correlation significant at the 0.01 level (1 tailed)

ERE: Emotional Recognition and Expression

In terms of the dimensions of emotional intelligence, Understanding Others Emotions, Emotions Direct Cognition and Emotional Control have a positive and significant relationship with Conscientiousness. It indicates that employees do take care in their work. This is shown in Table 3.

Having a high level of conscientiousness would help the organization in terms of its stability. However, in terms of Sportsmanship it has a negative and significant relationship with Understanding Others Emotions, Emotions Direct Cognition, Emotional Management and Emotional Control. Sportsmanship refers to putting up with minor inconveniences and not always finding fault with the organisation. Since it is negatively related, it indicates that the employees are not willing to put up with the minor inconveniences and they are always finding fault with the organisation. It could be that the situations that they have to put up with make them very uncomfortable. These situations that happened have a negative impact on their working attitudes [Mignonac and Herrbach 2004; Weiss and Cropanzano 1996]. These negative working attitudes would have an adverse effect on the work performance.
UOE: Understanding Others Emotions EDC: Emotions Direct Cognition EM: Emotional Management EC: Emotional Control

Civic Virtue has a positive and significant correlation with Understanding Others Emotions and Emotions Direct Cognition. It indicates that employees do care for their organisation's properties and they would not in any way harm these properties.

In terms of Courtesy, it has a positive and significant relationship with Emotional Recognition and Expression, Emotions Direct Cognition and Emotional Control. Courtesy refers to consulting people who would be affected by a decision or at the very least informing other people of such actions. In this case, it would seem that employees do care for their fellow colleagues and they will lend a helping hand as and when required. In terms of the organisation, this is a good indication. Altruism has a negative and significant relationship with Emotional Recognition and Expression but positive and significant relationship with the other dimensions of emotional intelligence. Altruism refers to the act of helping other fellow employees who are behind in their work. This help is voluntary. It can be interpreted that the employees are sometimes not aware of their fellow colleagues' needs especially in the times of problems. These colleagues of them could be trying to hide their difficulties or sometimes 
do not want help from their fellow colleagues. However, in general, it indicates that employees do care for their colleagues and would always lend a helping hand.

\section{Emotional Intelligence and Demographic Variables}

As shown in Table 4, the level of emotional intelligence has a positive and significant relationship with age. Dolcos [2008] and Chipain [2003] also report that older people have better control on their emotions and therefore have higher level of emotional intelligence. The findings disagree with Langhorn [2004] and Lim [2004] for they found that age did not have any impact on emotional intelligence.

Table 4: Relationship between the Level of Emotional Intelligence and Age

\begin{tabular}{|l|l|l|l|}
\hline & & Age Group & $\begin{array}{l}\text { Level of } \\
\text { Emotional } \\
\text { Intelligence }\end{array}$ \\
\hline Age Group & $\begin{array}{l}\text { Pearson } \\
\text { Correlation }\end{array}$ & 1 & $.280\left(^{* *}\right)$ \\
\hline & Sig. (1-tailed) &. & .003 \\
\hline & $\mathrm{N}$ & 96 & 96 \\
\hline
\end{tabular}

The findings agree with Dolcos [2008] and Scott [2004]. Older people do have a higher level of emotional intelligence. Younger generations tend to be rash and are not in control of their emotions. They could be single adults. Single adults may have less emotional support and could therefore be having problems accommodating at the workplace [Dunn 2003]. Older people have better emotional management as they have undergone experiences. Experiences gave them better understanding. As defined by Mayer and Salovey [1997], emotional intelligence refers to an ability to perceive emotions. The perception relates to the person's understanding ability. Emotional intelligence has a positive and significant relationship with the length of employment. This is as seen in Table 5. The longer the employee works in the organisation, the more familiar he or she is with the environment and the situations that he or she will encounter. The findings agree with Alloway [2004] where it is found that senior managers had a higher level of emotional intelligence than junior managers, as seen in Table 6.

Table 5: Relationship between the Level of Emotional Intelligence and Length of Employment

\begin{tabular}{|l|l|l|l|}
\hline & & $\begin{array}{l}\text { Employment } \\
\text { Length }\end{array}$ & $\begin{array}{l}\text { Level of } \\
\text { Emotional } \\
\text { Intelligence }\end{array}$ \\
\hline $\begin{array}{l}\text { Employment } \\
\text { Length }\end{array}$ & $\begin{array}{l}\text { Pearson } \\
\text { Correlation }\end{array}$ & 1 & $.186\left(^{*}\right)$ \\
\hline & Sig. (1-tailed) &. & .035 \\
\hline & $\mathrm{N}$ & 96 & 96 \\
\hline
\end{tabular}

* Correlation is significant at the 0.05 level (1-tailed). 
9 Journal of Human Resources Management Research

Table 6: Level of Emotional Intelligence and the Different Lengths of Employment

\begin{tabular}{|l|l|l|l|}
\hline Employment Length & Mean & N & Std. Deviation \\
\hline Less than 2 years & 203.4706 & 17 & 15.16624 \\
\hline $\begin{array}{l}\text { More than 2 years but } \\
\text { less than 5 years }\end{array}$ & 202.6852 & 54 & 9.32196 \\
\hline $\begin{array}{l}\text { More than 5 years but } \\
\text { less than 10 years }\end{array}$ & 201.2000 & 15 & 16.04102 \\
\hline More than 10 years & 215.8000 & 10 & 21.01745 \\
\hline Total & 203.9583 & 96 & 13.56149 \\
\hline
\end{tabular}

The average length of employment is 2.19 years which indicates that the workforce is made up of people who have just joined the organisation. This also indicates a high level of turnover in the organisation as the majority of people are within the 2 to 5 years category. Having a high turnover would affect the productivity of the organisation. This could also be part of the reason why emotional intelligence did not have a significant relationship with organizational citizenship behaviour. Employees could be affected by the traumatic events that have impacted their behaviours [Mignonac and Herrbach 2004; Weiss and Cropanzano 1996]. Their inability to manage these events pushed them towards leaving the organisation. If they have stayed longer in the organisation, they would have benefited and so would the organisation. Hence, SMEs do have a problem in retaining their employees.

Based on Table 7, employees from the Administration department have the highest level of emotional intelligence in comparison with those from the Maintenance department having the lowest level of emotional intelligence. Employees from the Administration department deal with human resource issues and have to be very good in their interpersonal skills. This indicates that the events that take place in the maintenance section might be very stressful such as having a high level of complaints, workload and long hours.

Table 7: Level of Emotional Intelligence and the Various Departments

\begin{tabular}{|l|l|l|l|}
\hline Department & Mean & N & Std. Deviation \\
\hline Administration and & 207.2000 & 15 & 16.94192 \\
\hline $\begin{array}{l}\text { Finance Accounting } \\
\text { Accoduction }\end{array}$ & 205.2000 & 10 & 12.62977 \\
\hline Prodes and Marketing & 201.9524 & 21 & 11.11728 \\
\hline Sales & 38 & 16.56042 \\
\hline Maintenance & 192.0000 & 2 & 14.14214 \\
\hline Engineering & 203.8000 & 5 & 14.30734 \\
\hline Others & 199.0000 & 5 & 7.84219 \\
\hline Total & 203.9583 & 96 & 13.56149 \\
\hline
\end{tabular}

Events that impact the working attitude would result in the employee taking drastic actions such as leaving the organisation [Kuchinsky 2006, Mignonac and Herrbach 2004; Weiss and Cropanzano 1996]. Highly stressful jobs affect employees [JobStreet 2009]. Based on the study, it is found that employees from the Accounting department have a lower level of emotional intelligence than those from the Finance and Accounting department. The findings support the results by Rozell et. al [2001], where it is found that accounting students had lower level of emotional intelligence than those in 
management and finance. The level of emotional intelligence could be related to the nature of work involved. The higher the stress level, the lower the level of emotional intelligence. As indicated by Mignonac and Herrbach [2004], work events have an impact on the person's effective state and attitude. Respondents in the Accounting department are exposed to stressful working conditions in comparison with those in the Administrative department.

\section{Discussion}

The first research objective is to examine the relationship between emotional intelligence and organizational citizenship behaviour. The second research objective was to investigate the relationship between emotional intelligence and the demographic variables particularly age, length of employment and department. It is found that emotional intelligence does not have a significant relationship with organizational citizenship behaviour. Age and length of employment has a positive and significant relationship with emotional intelligence. Employees from the Administration department have the highest level of emotional intelligence in comparison with those from the Maintenance department. Significant traumatic events that take place which severely impact the employee's feelings will have a serious effect on the working attitude [Kuchinsky 2006, Mignonac and Herrbach 2004; Weiss and Cropanzano 1996].

Results from the study show that employees in SMEs do experience some kind of experiences that have affected their working attitudes. A majority of them have not worked long in the organisation. The average length of work in the organisation is 2.19 years. As such they would not be able to give a more conclusive result. It would be helpful and beneficial for SMEs to take advantage of the Human Resource Development Fund organized by the Ministry of Human Resource, Malaysia to train and develop their employees. Many of SMEs have not fully utilized their funds [The Star 2007]. The aim of the fund is to improve the organisation's level of productivity. Many SMEs shy away from training as they are afraid that these employees would leave for another organisation. In general, Malaysian graduates lack dynamism [The Star 2009a]. This can be seen in terms of the dimensions of emotional intelligence and organizational citizenship behaviour. The Malaysian government intends to increase the tertiary educated employees by $13 \%$ that is from $20 \%$ to $33 \%$ by 2010 [The Star 2008].

\section{Conclusion and Area of Future Research}

Results from the initial study provide many insights especially to the areas where respondents showed a low level of emotional intelligence. The low level of emotional intelligence is related to the nature of work involved especially when it involves a high level of stress. The higher the stress level, the lower the level of emotional intelligence. This is evident in the Maintenance department. Executives in the Maintenance department have to ensure that the machines in the production area are functioning well. If the machines malfunction, the production will be affected. Management can take heed from these findings by sending the executives for training on soft skills management. SMEs represent the backbone of the industry. Despite their contribution to the economy, SMEs problems are largely human resource related. They are unable to attract and retain employees. Hence, the purpose of the research is to explore the level of emotional intelligence among executives in SMEs particularly those from the manufacturing sector.

The present study has certain limitations. In terms of the sample size, the study only managed to get about 8 companies to participate in the survey and not all types of industries took part. One of the reasons is that some companies do not have many people working. For example, in terms of furniture manufacturing companies, they have about 5 people working in the office, 2 
of them are the owners and the remaining 3 are the clerical employees. Some of the employees are family related. As such, these companies were not included as the employees' responses would be biased. Certain precaution needs to be taken in terms of the results especially in terms of the departments. Not many organisations have all the departments. For example, Maintenance had only 2 responses as compared with other departments like Production which has 38 responses.

Only 96 questionnaires were able to be used; others had to be discarded as employees gave partial answers. The study could be further improved by increasing the sample size. Having a longitudinal study to measure the increase in the level of emotional intelligence especially in the problem departments would also be helpful. Longitudinal study would enhance the research by having a before and after results in the levels of emotional intelligence. It could also shed more light in terms of the influencing effects of the environment that the employee works in.

\section{Acknowledgment}

Many thanks to those who were instrumental in the completion of this paper. You have provided the inspiration and also the determination to move on.

\section{References}

Abdul Hamid, A. B., Baharun, R. \& Hashim, N. H. (2008). 'Comparative Analysis of Managerial Practices in Small Medium Enterprises in Malaysia,' Retrieved 14 March 2009 from

http://www.fppsm.utm.my/files/jurnal/JK08 /804.pdf

Abraham, R. (2000). "The Role of Job Control as a Moderator of Emotional Dissonance and Emotional Intelligence - Outcome Relationships," Journal of Psychology, Vol. 134, pp 169-184
Alloway, B. M. (2004). "Emotional Intelligence and Extrinsic Career Success: A Comparison of Gender and Management," Gannon University

Boncher, M. K. (2003). 'The Relationship between Attachment Styles and Emotional Intelligence,' New York University.

Brooks, J. K. (2002). "Emotional Competencies of Leaders: A Comparison of Managers in Financial Organisation by Performance Level," (A Doctoral Dissertation) North Carolina State University.

CCM (2002). 'Companies Commission of Malaysia, Statistics of Insolvency Completed,' Retrieved 13 March 2009 from http://www.ssm.com.my

Chipain, G C. (2003). 'Emotional Intelligence and Its Relationship with Sales Success,' (A Doctoral Dissertation) De Paul University.

Cooper, R. (1998). "Sentimental Value," People Management 4(7) 48-51.

Deloitte Kassim Chan (2009). 'Companies Urged to Identify the MNCs they Seek to Support,' [Retrieved 13 March 2009 from http://www.deloitte.com/dtt/press_release/0, 1014,sid\%253D34169\%

Deshpande, S. P. \& Joseph, J. (2005). "The Impact of Emotional Intelligence on Counterproductive Behaviour in China," Management Research News, Volume 28 Number 5 Pages $75-85$.

Dolcos, F. (2008). "Wisdom Comes with Age, at Least When it Comes to Emotions," ScienceDaily. University of Alberta, Faculty of Medicine and Dentistry. Retrieved 15 July 2008 from

http://www.sciencedaily.com/releases/2008/ 06/080612185428.htm

Douglas, C., Frink, D. D., Ferris, G. R. (2004). "Emotional Intelligence as a Moderator of the Relationship between Conscientiousness and Performance," Journal of Leadership and Organisational Studies, Volume 10, No. 3 
Dunn, S. (2003). "Demographic Trends, the Bottom Line, and the Case for Emotional Intelligence in the Workplace," Retrieved 20 March 2009 from

http://www.webpronews.com/node/2523/p rint]

Gardner, L. \& Stough, C, (2002). "Examining the Relationship between Leadership and Emotional Intelligence in Senior Level Managers," The Leadership and Organization Development Journal, 23, 68-78.

JobStreet (2009). "HR Corner: Miscellaneous," Retrieved 12 March 2009 from http://my.jobstreet.com/employers/misc.htm

Kuchinsky, C. (2006). "The Most Stressful Jobs in America," Stress in the American Workplace. Retrieved 15 June 2008 from http://www.associatedcontent.com/article/9 2667/the_most_stressful_jobs_in_america.ht $\mathrm{ml}$

Langhorn, S. (2004). "How Emotional Intelligence Can Improve Management Performance," International Journal of Contemporary Hospitality Management, Volume 16, No. 3, Pp 220-230.

Lim, H. H. (2004). 'Significance of Knowledge Worker's Emotional Intelligence in Organisations,' Multimedia University.

Mayer, J. D. \& Salovey, P. (1997). 'What is Emotional Intelligence?,' In P. Salovey and D. Sluyter (Eds.), Emotional development and emotional intelligence (pp3-31) New York: Basic Books.

Mignonac, K., Herrbach, O. (2004). "Linking Work Events, Affective States, and Attitudes: An Empirical Study of Managers' Emotions," Journal of Business and Psychology, Vol 19 No.2, pp.221-40.

MSDC (2007). 'Malacca State Development Corporation,' List of Name and Addresses of Companies in the Industrial Estates.
Mustapha, R. \& Abdullah, A. (2005). 'Malaysia Transition Towards a Knowledge-Based Economy,' Journal of Technology Studies, pp 51-61

Palmer, B. (2003). 'Measures of Emotional Intelligence in the Workplace - A Comparative Analysis,' Swinburne University, Australia

Palmer, B. \& Stough, C. (2001). 'Swinburne University Emotional Intelligence Test,' Interim Technical Manual. Organistional Psychology Research Unit.

Pasanen, S. E. (2000). 'Emotional Intelligence, Conscientiousness and Integrity as Predictors of Organisational Citizenship Behaviour,' Doctoral Dissertation. California State University, Long Beach.

Podsakoff, P. M., Mackenzie, S. B., Moorman, R. H. \& Fetter, R. (1990). "Transformational Leaders Behaviour and their Effects on Followers' Trust in Leader, Satisfaction and Organizational Citizenship Behaviours," Leadership Quarterly 1, 107-142.

Rose, R. C., Kumar, N. \&Yen, L. L. (2006). "Entrepreneurs Success Factors and Escalation of Small and Medium-sized Enterprises in Malaysia," Journal of Social Sciences, 2(3): 74-80.

Rozell, E. J., Pettijohn, C. E. \& Parker, R. S. (2001). "An Empirical Evaluation of Emotional Intelligence: The Impact on Management Development," Journal of Management Development, Volume 21, No.4.

Scott, B. S. (2004). 'The Relationship between EI and Ethical Decision Making,' $A$ PhD Dissertation, Union University.

Sitter, V. L. (2004). 'The Effects of a Leadership Emotional Intelligence on Employees' Trust in Their Leader and Employee Organisational Citizenship Behaviours,' Doctoral Dissertation. Regent University SMIDEC (2009) Profile of SMEs in the Manufacturing 
13 Journal of Human Resources Management Research

Sector, Retrieved 12 March 2009 from http://www.smidec.gov.my/detailpage.jsp?pa ge $=$ statistic

The Star (2007). "Training One's Employees Is Worth the Investment," September 9, 2007.

The Star (2008). "Graduates to form 33\% of Workforce by 2010," April 22, 2008.

The Star (2009a). "Subra: Graduates Lack Dynamism and Edge," February 16, 2009.

The Star (2009b). "Crucial to Engage Staff," March 10, 2009.

Watson Wyatt Malaysia (2009). 'Asia-Pacific Leads in Pay Hikes,' Retrieved 16 March 2009 from http://www.watsonwyatt.com/asiapacific/localsites/malaysia/news/press.asp?I $\mathrm{D}=18981$

Weiss, H. M. \& Cropanzano, R. (1996). "Affective Events Theory: A Theoretical Discussion of the Structure, Causes and Consequences of Affective Experiences at Work," in Cummings, L.L. (Eds), Research in Organizational Behavior, JAI Press, Greenwich, CT, Vol. Vol. 19 pp.1-74. 